\title{
Cognitive Assessment of Patients With Alzheimer's Disease by Telemedicine: Pilot Study
}

Anna Carotenuto ${ }^{1}, \mathrm{PhD}$; Raffaele Rea ${ }^{1}, \mathrm{PhD}$; Enea Traini ${ }^{1}, \mathrm{PhD}$; Giovanna Ricci ${ }^{2}, \mathrm{MA}$; Angiola Maria Fasanaro ${ }^{3}$, MD; Francesco Amenta ${ }^{1}$, MD

${ }^{1}$ Clinical Research, Telemedicine and Telepharmacy Centre, School of Pharmacy, University of Camerino, Camerino, Italy

${ }^{2}$ Bioethics and Legal Medicine Centre, School of Law, University of Camerino, Camerino, Italy

${ }^{3}$ Neurology Unit, National Hospital (Antonio Cardarelli), Naples, Italy

\section{Corresponding Author:}

Enea Traini, $\mathrm{PhD}$

Clinical Research, Telemedicine and Telepharmacy Centre

School of Pharmacy

University of Camerino

Via Madonna delle Carceri no 9

Camerino, 62032

Italy

Phone: 390737401725

Email: enea.traini@unicam.it

\section{Abstract}

Background: Approximately 46.8 million people are living with dementia worldwide and their number will grow in the next years. Any potential treatment should be administered as early as possible because it is important to provide an early cognitive assessment and to regularly monitor the mental function of patients. Information and communication technologies can be helpful to reach and follow patients without displacing them, but there may be doubts about the reliability of cognitive tests performed by telemedicine.

Objective: The purpose of this study was to evaluate the reliability of the Mini Mental State Examination (MMSE) and the Alzheimer's Disease Assessment Scale cognitive subscale (ADAS-cog) tests administered in hospital by videoconference to patients with mild to moderate Alzheimer's disease.

Methods: The tests were administered to 28 Alzheimer's disease outpatients ( 8 male, mean age 73.88, SD 7.45 years; 20 female mean age 76.00, SD 5.40 years) recruited and followed in the Alzheimer's Unit of the A Cardarelli National Hospital (Naples, Italy) at baseline and after 6, 12, 18, and 24 months of observation. Patients were evaluated first face-to-face by a psychologist and then, after 2 weeks, by another psychologist via videoconference in hospital.

Results: This study showed no differences in the MMSE and ADAS-cog scores when the tests were administered face-to-face or by videoconference, except in patients with more pronounced cognitive deficits (MMSE<17), in which the assessment via videoconference overestimated the cognitive impairment (face to face, MMSE mean 13.9, SD 4.9 and ADAS-cog mean 9.0, SD 3.8; videoconference, MMSE mean 42.8, SD 12.5 and ADAS-cog mean 56.9, SD 5.5).

Conclusions: We found that videoconferencing is a reliable approach to document cognitive stability or decline, and to measure treatment effects in patients with mild to moderate dementia. A more extended study is needed to confirm these results.

(JMIR Ment Health 2018;5(2):e31) doi: 10.2196/mental.8097

\section{KEYWORDS}

dementia; telemedicine; videoconference; telepsychology; MMSE by videoconference; ADAS-cog by videoconference

\section{Introduction}

Approximately 46.8 million people are living with dementia worldwide and it is expected that this figure will double every 20 years [1]. The number of people affected by dementia will probably reach 74.7 million in 2030 and 131.5 million in 2050 [2]. Alzheimer's disease (AD) is the most common type of dementia, representing between $60 \%$ and $80 \%$ of dementia cases [3]. The costs of this disease are very high now and will become even higher in the future, and will impact severely, directly, 
and indirectly on health systems and patients' families [4]. No therapy has been found to stop dementia progression, but any potential treatment should be administered as early as possible. Therefore, it is crucial to provide a cognitive assessment of elderly patients as early as possible and continue monitoring it [5-7]. Information and communication technologies have been employed in dementia and they are particularly helpful [8], allowing physicians, psychologists, and nurses to reach patients without displacing them $[9,10]$. Several studies have evaluated the use of telemedicine for dementia disorders, but doubts still exist about the reliability of cognitive tests applied by videoconference [11,12].

In this field, telemedicine shows benefits and limitations. Among the benefits, there is the possibility to include patients who prefer to stay at home rather than going to the hospital or clinics [13] and for their caregivers to not be alone in providing better care. Costs and the displacement of patients can be reduced, more frequent monitoring can be assured, and waiting lists and hospital staff work are lowered and the caregiver time is preserved [14]. These benefits justify why cognitive assessment via videoconferencing is potentially useful and valid in dementia patients.

However, telemedicine also has some risks: older adults are frequently resistant to use new technologies and their use requires necessary skills. The security of sensitive data, the identification of the evaluator, and the quality of data transmission may represent further limitations [15].
The main concern is the reliability of data obtained by telemedicine. The assessment of $\mathrm{AD}$ requires the evaluation of cognitive functions, which is done through specific tests. These include the Mini Mental State Examination (MMSE), the most used for clinical purposes, and the Alzheimer's Disease Assessment Scale cognitive subscale (ADAS-cog), the most used for measuring the effect of treatments. The feasibility of the MMSE by videoconference has been investigated by several authors [16-23] (Table 1). One of these studies was done in an Italian population. No differences were reported between the scores obtained when the MMSE was administered face-to-face versus videoconference, except in one study in which it was found for $40 \%$ of the patients the videoconference MMSE was two points lower than the face-to-face MMSE [21].

The majority of previous studies have considered mild to moderate $\mathrm{AD}$ outpatients, living in different contexts, more often in rural areas. All studies have used the traditional 30-item MMSE, except one which has used a 28-item MMSE [17]. In summary, MMSE studies in videoconference have not yet evaluated the follow-up of $\mathrm{AD}$ patients. No study, to our knowledge, has evaluated the reliability and feasibility of the ADAS-cog test by videoconference modality. Moreover, the feasibility of MMSE has not been fully evaluated. On this basis, we wanted to assess if MMSE and ADAS-cog are reliable at follow-up.

Table 1. Articles reviewed on "cognition screening tests by telemedicine" that used videoconferencing. AD: Alzheimer's disease; GDS: Global Deterioration Scale; MCI: mild cognitive impairment; MMSE: Mini Mental State Examination; VMMSE: Videoconference-based Mini Mental State Examination.

\begin{tabular}{lllll}
\hline Authors & Year & Demographics of patients & Patients investigated & Results \\
\hline Cullum et al [22] & 2014 & $\begin{array}{l}\text { N=202; age: mean 68.5 (SD 9.5) years; } \\
\text { education: mean 14.1 (SD 2.7) years }\end{array}$ & $\begin{array}{l}59 \% \text { healthy controls and } \\
41 \% \text { with MCI or AD }\end{array}$ & $\begin{array}{l}\text { VMMSE and face-to-face MMSE was } \\
\text { comparable (with the score is }>15)\end{array}$
\end{tabular}

Kim et al [16] 2017

$\mathrm{N}=188$; age: mean 78 (SD 24) years; education: telemedicine ( 2.4 years) and face-to-face (3.4 years)

Timpano et al [17] $\quad 2013$

Ciemins et al [18] 2009

Mc Eachern et al [20] 2008

Loh et al [19]
$\mathrm{N}=342$ (134 male); age: range 50-94 years; education: range $0-18$ years

$\mathrm{N}=63$ (45\% female); age: mean 61 years (range 36-90) years

$\mathrm{N}=20$ (9 male); age: range $65-79$ years

Cognitively impaired

Demented healthy patients associated depression 9 normal
$\mathrm{N}=71$ (34 male); age: mean 72 (SD 11) years

Cognitively impaired and

Type 2 diabetics, $17 \%$ with

$37 \mathrm{AD}, 11 \mathrm{MCI}, 4$ vascular dementia, 10 other pathology,

Loh et al [21] 2004 comparable (with the score is $>15$ )

The mean annual VMMSE changes were less than the mean face-to-face MMSE score changes ( 0.60 vs 1.03 points), but not statistically significant. More than $95 \%$ of participants were treated with cholinesterase inhibitors

VMMSE is comparable with face-to-face MMSE, but with cut-off 28

$\geq 95 \%$ concordance in the $80 \%$ of the items of VMMSE with face-to-face MMSE

No difference between VMMSE and faceto-face $(P=.23)$

The mean face-to-face MMSE was 23.3 (SD 3.6), MMSE by videoconference was 24.2 (SD 3.7)

VMMSE yielded similar results to faceto-face MMSE in $60 \%$ of patients; however, there was a moderate difference in $40 \%$ of two points or more on the MMSE on face-to-face MMSE

Mean scores VMMSE (22.2) were similar with face-to-face MMSE (23.7) 
On this basis, our aims were (1) to evaluate if the videoconference administration of MMSE and ADAS-cog were comparable to the face-to-face administration, and (2) to assess the acceptance of patients and caregivers of the videoconference modality. Our study was focused on these aspects and not on the diagnosis of $\mathrm{AD}$ that in the majority of cases requires more extensive and articulated diagnostic procedures.

\section{Methods}

\section{Participants}

The study sample consisted of 28 AD outpatients (8 male, 20 female) followed by the Alzheimer and Neurodegenerative Diseases Unit, Neurology Department, A Cardarelli National Hospital in Naples, Italy. Supervision, organization, and informatics support and statistics were provided by the Clinical Research Centre of Camerino University in Camerino, Italy. Clinical diagnosis of $\mathrm{AD}$ was performed by a neurologist according to the National Institute of Neurological and Communicative Disorders and Stroke and the Alzheimer's Disease and Related Disorders Association criteria. Moreover, brain magnetic resonance imaging was used to confirm the diagnosis. The severity of dementia was assessed by the MMSE, the Activities of Daily Living (ADL), the Instrumental Activities of Daily Living (IADL), the Clinical Dementia Rating, and other neuropsychological tests scores.

Inclusion criteria were age older than 50 years, MMSE score between 24 and 12, education for more than 5 years, good visual-hearing ability, and living with or in contact with a caregiver willing to cooperate in the evaluation of effectiveness. All patients were community dwelling and were enrolled in the study at least 6 months after the diagnosis. Exclusion criteria were decompensated heart disease, chronic renal failure, severe liver failure, uncorrected dysthyroidism, cancer; diagnosis of major depression (according to DSM-IV criteria), and a different diagnosis of AD. Patients were randomly recruited among outpatients followed by the Alzheimer and Neurodegenerative Diseases Unit.

The mean age of male patients was 73.88 (SD 7.45) years and of female patients was 76.00 (SD 5.40) years. All 28 patients had a mean education of 7.61 (SD 4.07) years. Sixteen patients were widowed and 12 were married. All were retired and lived at home, with 12 patients living with their spouse, 11 with a child, and 5 with non-family caregivers. Six patients were left-handed. Comorbid health conditions were high blood pressure $(n=27)$, hypercholesterolemia $(n=26)$, diabetes $(n=4)$, and ischemic cardiopathy $(\mathrm{n}=6)$. No patients had comorbidities of psychiatric disorders, although 14 patients had anxiety. All patients and their caregivers signed an informed consent form. A questionnaire developed specifically for this study was used to assess the level of acceptance of the telehealth procedures. This study was reviewed and approved by the ethical committee of A Carderelli Hospital.

\section{Tests and Questionnaire}

The Italian versions of the MMSE [24] and ADAS-cog [25] were used for each participant in both the face-to-face and videoconference modalities.
The MMSE is a brief, quantitative measure of the cognitive status of adults. It can be used to screen for cognitive impairment, to estimate the severity of cognitive impairment at a given point in time, to follow the course of cognitive changes in an individual over time, and to document a patient's response to treatment. It consists of 30 items (questions), which refer to seven different cognitive areas: time orientation, spatial orientation, registration, attention and calculation, recall, language, and praxis. The total score ranges from a minimum of zero and a maximum of 30 points [26]. The normative study in an Italian elderly population found that a score of 24 or less, corrected by age and educational level using the score-adjustment coefficients, is suggestive of dementia; lower scores indicate greater cognitive impairment [24]. Administration time is approximately 10 to 15 minutes. A meta-analysis showed that the MMSE has a sensitivity of $79.8 \%$, a specificity of $81.3 \%$, a positive predictive value of $86.3 \%$, and a negative predictive value of $73.0 \%$ for dementia [27]. For conversion from mild cognitive impairment (MCI) to AD, the accuracy of MMSE scores ranged from sensitivities of $27 \%$ to $89 \%$ and specificities from $32 \%$ to $90 \%$ [28].

The ADAS-cog measures the cognitive performance of six broad areas of cognition: memory; language; ability to orient oneself to time, place, and person; construction of simple designs and planning; and performing simple behaviors in pursuit of a basic, predefined goal [29]. The ADAS-cog is scored from zero to 70; higher scores indicate greater cognitive impairment. Administration time is approximately 30 to 45 minutes. The Italian study of ADAS-cog on psychometric and normative data was based on a sample of 95 healthy volunteers. Results indicated a specific influence of patient educational level on the cognitive subscale total score of ADAS and the need for an adequate correction was observed [25]. The ADAS-cog cut-off score for dementia was 12 or less with sensitivity and specificity values of $89.19 \%$ and $88.53 \%$, respectively [30]. The best cut-off score of ADAS-cog to distinguish between MCI and AD was 12 or higher with sensitivity of 0.86 , specificity of 0.89 , positive predictive values of 0.99 , and negative predictive values of 0.32 [31].

A questionnaire on the acceptance of the videoconference modality for cognitive testing included five questions with a response ranging from 1 to 5 , where $1=$ I strongly disagree and $5=I$ strongly agree. This questionnaire assessed the experience of videoconferencing, including an overall evaluation, if participants wanted to repeat the experience, attitudes toward data privacy, and clarity of instructions. The questionnaire was administered to both the patient and the caregiver.

\section{Materials and Videoconferencing System Utilized in Hospital}

Two Sony VAIO laptops were used for videoconferencing and data collection. The Sony VAIO laptops contained an IntelCore Duo CPU P8400 2.26 GHz processor, 4 GB memory, Intel Media Accelerator X3100 graphics card, and a 17.3" LCD LED $(1920 \times 1080)$ integrated screen. The videoconferencing system used was the BCC950 Logitech, with integrated microphone and video camera. Computers operated under the corporate domain, restriction of use policies, and antivirus systems. 
Administration of the MMSE and ADAS-cog tests took place through real-time videoconferencing, on both terminals, with Microsoft Skype. Connection speed of the local area network of Cardarelli Hospital connection averaged $100 \mathrm{Mbit} / \mathrm{s}$ and had perimeter firewalls to guarantee security protection of the connection.

To evaluate the reliably of the videoconference, both the psychologist's and patient's computers were connected to the same LAN. Videoconference ensured high levels of security and encrypted communication. Patients were prepared in advance for the possibility of occasional technological problems, such as when calls "drop out" or the video image becomes frozen. Remote control of the audiovisual system was done with Virtual Network Computing software.

\section{Procedure}

After obtaining informed consent by a research assistant, the MMSE and ADAS-cog tests were administered by face-to-face assessment and videoconference modalities. Both the face-to-face and videoconference assessments were done in the hospital. Tests were administered at baseline and after 6, 12, 18 , and 24 months. All patients had been previously diagnosed in the Alzheimer Unit of Cardarelli Hospital by a neurologist. The screening for eligibility criteria was made by the neurologist. Patients were evaluated first face-to-face by a psychologist for inclusion criteria (MMSE score between 24 and 12). For each patient, tests were administered five times (baseline and after 6, 12, 18, and 24 months) in both face-to-face and videoconference modalities. The interval between each administration was 2 weeks to minimize any practice effect. The administration was done by two blinded psychologists independently (rater 1 and rater 2).

In the task of "naming objects," real objects were used, whereas the "close your eyes" command was presented in full screen and shown to the patient via the webcam as well as the pentagon drawing task. Psychologists were trained in administering the MMSE and ADAS-cog by face-to-face and by videoconference, and had more than 10 years' of experience. Caregivers were not present during the cognitive assessments, but an assistant was present in case of technical issues.

The videoconference modalities took place in a hospital room equipped with the instruments and an informatics operator participated to check if the visual and audio settings were adequate. The time required in both conditions (face-to-face and videoconference) was also measured.

\section{Statistics}

The ANOVA test was used to assess if the administration modality (independent variable) was associated with any difference in total scores of MMSE and ADAS-cog tests (dependent variables). A further analysis considered the subgroups of patients according to their MMSE at baseline. For this analysis, they were grouped by MMSE score as slightly impaired (score 21-24), moderately impaired (score 18-20), and severely impaired (score 15-17). The ANOVA test was used for assessing the significance of differences between the preceding patient groups.

\section{Results}

A total of $28 \mathrm{AD}$ patients (8 male, 20 female) with a mean baseline MMSE of 19.6 (SD 3.0), ADL mean 3.1 (SD 1.0), and IADL mean 2.0 (SD 0.8) were evaluated by administering the MMSE and ADAS-cog in both a face-to-face and videoconference modality. All participants reached the end of the study period of 2 years.

Baseline and follow-up MMSE scores obtained by face-to-face or videoconference modality are summarized in Table 2. As shown, no significant differences were noticeable between face-to-face or videoconference testings. The same was true for baseline and follow-up ADAS-cog scores, shown in Table 2. The time required for performing the tests was also comparable, with mean 37 (SD 8) minutes in the face-to-face modality and mean 38 (SD 10) minutes in the videoconferencing modality.

Data derived from the MMSE and ADAS-cog tests were also analyzed separately, dividing patients into three groups according to their MMSE scores at baseline recorded at the enrollment (eg, severely impaired, moderately impaired, and slightly impaired). As shown in Table 3, at baseline and follow-up, the two modalities did not influence the MMSE scores of the first and second groups of patients. Patients in the third group, who had a lower MMSE, obtained lower scores by the videoconference modality compared to the face-to-face modality. The same differences were observed in the ADAS-cog test (Table 4) with patients in the third group having higher scores by videoconference than in the face-to-face modality. 
Table 2. The Mini Mental State Examination (MMSE) and Alzheimer's Disease Assessment Scale cognitive subscale (ADAS-cog) values obtained by face-to-face or videoconference modalities.

\begin{tabular}{|c|c|c|c|c|c|}
\hline Tests & Baseline & 6 months & 12 months & 18 months & 24 months \\
\hline \multicolumn{6}{|l|}{ MMSE } \\
\hline Face-to-face, mean (SD) & $19.6(3.0)$ & $19.5(5.0)$ & $18.4(5.8)$ & $18.3(6.1)$ & $17.8(6.8)$ \\
\hline Videoconference, mean (SD) & $18.8(4.5)$ & $18.7(5.4)$ & $17.7(6.5)$ & $17.3(7.1)$ & $16.3(7.7)$ \\
\hline$P$ value & .37 & .56 & .68 & .61 & .42 \\
\hline \multicolumn{6}{|l|}{ ADAS-cog } \\
\hline Face-to-face, mean (SD) & $28.6(19.3)$ & $29.3(19.8)$ & $31.9(20.3)$ & 33.9 (20.7) & $34.8(20.0)$ \\
\hline Videoconference, mean (SD) & $34.1(17.4)$ & $34.5(17.4)$ & $36.5(17.4)$ & $39.7(15.1)$ & $40.4(13.5)$ \\
\hline$P$ value & .07 & .07 & .19 & .12 & .17 \\
\hline
\end{tabular}

Table 3. The Mini Mental State Examination (MMSE) values obtained by face-to-face or videoconference in patients with baseline MMSE showing slight (21-24), moderate (18-20), or severe (15-17) impairment.

\begin{tabular}{llllll}
\hline MMSE impairment level & Baseline & 6 months & 12 months & 18 months & 24 months \\
\hline Slight & & & & & \\
$\quad$ Face-to-face, mean (SD) & $23.0(1.1)$ & $24.5(3.2)$ & $24.6(2.7)$ & $25.4(2.5)$ & $24.7(3.3)$ \\
$\quad$ Videoconference, mean (SD) & $23.1(1.5)$ & $24.30(2.3)$ & $24.5(2.3)$ & $25.6(2.5)$ & $24.7(2.9)$ \\
$\quad \begin{array}{l}P \text { value } \\
\text { Moderate }\end{array}$ & .87 & .88 & .93 & .93 & $>.99$ \\
$\quad$ Face-to-face, mean (SD) & $19.3(0.9)$ & $18.0(2.2)$ & $16.4(2.9)$ & $16.1(2.9)$ & $14.1(5.1)$ \\
$\quad$ Videoconference, mean (SD) & $19.0(1.2)$ & $18.3(2.1)$ & $17.1(2.8)$ & $16.2(3.1)$ & $14.1(4.9)$ \\
$\quad P$ value & .51 & .75 & .63 & .94 & $>.99$ \\
Severe & & & & $13.2(3.9)$ & $13.9(4.9)$ \\
$\quad$ Face-to-face, mean (SD) & $16.1(0.8)$ & $15.4(3.9)$ & $13.3(3.9)$ & $10.2(3.7)$ & $9.0(3.8)$ \\
$\quad$ Videoconference, mean (SD) & $12.7(1.5)$ & $12.8(2.6)$ & $10.7(3.8)$ & .11 & .03 \\
$\quad P$ value & $<.001$ & .11 & & .17 \\
\hline
\end{tabular}

Table 4. The Alzheimer's Disease Assessment Scale cognitive subscale (ADAS-cog) values obtained by face-to-face or videoconference in patients with baseline Mini Mental State Examination (MMSE) showing slight (21-24), moderate (18-20), or severe (15-17) impairment.

\begin{tabular}{|c|c|c|c|c|c|}
\hline MMSE impairment level & Baseline & 6 months & 12 months & 18 months & 24 months \\
\hline \multicolumn{6}{|l|}{ Slight } \\
\hline Face-to-face, mean (SD) & $22.5(5.7)$ & $21.8(3.8)$ & $22.5(9.7)$ & $23.8(11.1)$ & $24.0(11.4)$ \\
\hline Videoconference, mean (SD) & $23.0(5.3)$ & $22.0(3.5)$ & $22.8(6.8)$ & $26.0(12.8)$ & $24.5(11.6)$ \\
\hline$P$ value & .84 & .90 & .94 & .70 & .92 \\
\hline \multicolumn{6}{|l|}{ Moderate } \\
\hline Face-to-face, mean (SD) & $29.2(4.4)$ & $31.8(4.8)$ & $34.0(5.7)$ & $35.6(7.2)$ & $38.8(10.5)$ \\
\hline Videoconference, mean (SD) & $30.2(4.9)$ & $33.0(4.1)$ & $34.9(5.1)$ & $38.7(6.7)$ & $41.4(9.5)$ \\
\hline$P$ value & .65 & .57 & .73 & .36 & .58 \\
\hline \multicolumn{6}{|l|}{ Severe } \\
\hline Face-to-face, mean (SD) & $34.9(7.0)$ & $35.1(7.3)$ & $40.3(9.5)$ & $42.4(10.3)$ & $42.8(12.5)$ \\
\hline Videoconference, mean (SD) & $52.4(7.6)$ & $49.9(6.9)$ & $53.2(7.7)$ & $54.6(6.7)$ & $56.9(5.5)$ \\
\hline$P$ value & $<.001$ & $<.001$ & .01 & .01 & .01 \\
\hline
\end{tabular}


Table 5. Results of the questionnaire ${ }^{\mathrm{a}}$ on acceptance of the videoconference modality for cognitive testing.

\begin{tabular}{lll}
\hline Questions & Patients, mean (SD) & Caregivers, mean (SD) \\
\hline 1. Instructions are clear and understandable & $4.4(1.3)$ & $4.6(0.9)$ \\
2. Data privacy is assured & $4.8(0.6)$ & $4.5(1.1)$ \\
3. I saved my time & $4.0(0.8)$ & $4.8(0.5)$ \\
4. I would like to repeat the experience & $4.5(0.8)$ & $4.3(1.3)$ \\
5. I prefer the Web modality than coming to the hospital & $3.3(1.5)$ & $4.3(1.5)$ \\
\hline
\end{tabular}

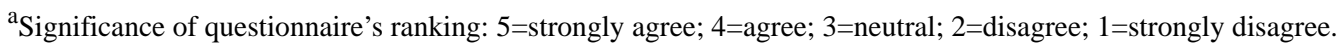

The acceptance of videoconference examination documented by a short questionnaire was quite high, with both patients and caregivers appreciating this modality. In particular, the preference for the web modality versus coming to the hospital was very high for both patients (mean 3.3, SD 1.5) and caregivers (mean 4.3, SD 1.5; Table 5).

\section{Discussion}

In this study, we evaluated the reliability and feasibility of the MMSE and ADAS-cog tests by videoconference in mild to moderate AD outpatients. Two blinded raters administered the tests by face-to-face and videoconference modalities and compared the results. The MMSE results were the same in the two modalities. Only in nine patients with more pronounced cognitive deficits $(\mathrm{MMSE}<17)$ did the videoconference modality overestimate the impairment.

The results from the MMSE are consistent with findings reported by other studies [16-23]. Most studies evaluated patients affected by dementia or MCI, except in one study [18] that examined the reliability of MMSE administration via remote administration in a group of 72 patients with diabetes. These studies did not find differences between the scores of the MMSE administered face-to-face versus videoconference or telephone interviews [16-23]. In contrast to a larger previous study by another group [17], we used the traditional 30-item MMSE, which includes the writing and drawing tasks.

For the ADAS-cog test, this is the first study, to our knowledge, using a videoconference modality. In our investigation, we observed that the face-to-face or videoconference modalities did not influence the ADAS-cog scores of the first and second group of patients (MMSE scores 21-24 and 18-20, respectively), whereas patients in the third group, who had a lower MMSE (15-17), obtained more severe (higher) scores by videoconference compared to the face-to-face modality. This is probably due to the difficulty of understanding the meaning of specific questions. These findings suggest using the videoconference modality with patients with mild to moderate $\mathrm{AD}$ and excluding those with a moderate to severe AD.

Videoconferencing has been shown to be reliable not only in $\mathrm{AD}$, but to assess the cognitive functions in other pathologies. Interesting results were provided for psychiatric patients [32-33], patients with Parkinson disease [34], and stroke patients [35], as well as in older adults [36]. Furthermore, videoconferencing has been found useful to evaluate the clinical status [37] and rehabilitation [38] of patients affected by different neurological disorders. All the preceding studies confirm that videoconference instructions are clear enough. This also was observed in our sample of patients, who reported that for saving time they preferred the teleconference modality than coming to the hospital. That is one good reason for supporting the videoconference approach. The patients and their caregivers were informed that videoconference evaluation ensured high levels of security and encrypted communication. From responses to the questionnaire on acceptance, they did not have concerns about the privacy of their medical information. The acceptability of the videoconference modality in this study is consistent with previous investigations in $\mathrm{AD}$, which reported that $98 \%$ of the patients were satisfied and felt at ease with it [32,39].

Previous studies found that women, older patients, and less educated patients may be less receptive to technology. In contrast, men, younger patients, and those with higher education are more receptive to telemedicine and report less anxiety $[40,41]$. The link found between education and technology acceptability is worth being considered. Studies have revealed that higher levels of education are associated with higher levels of both computer knowledge and computer interest and lower levels of computer anxiety [42].

The range of settings where videoconferencing can be used is wide and it can represent a useful and effective method for assessing cognitive functions. However, continued validation studies and adaptation of neuropsychological instruments is warranted.

Ethical and legal consequences of assessing cognitive functions via telemedicine deserve to be discussed as well. Caring for patients suffering from dementia poses complex ethical problems because of the nature of dementia and the way that dominant ethical principles apply to its clinical features [43]. These problems include informed consent, the duty to maintain the confidentiality, and privacy of patient examination and records [44-48]. In this study, patients and/or their caregivers were informed about potentiality and the limits of the videoconference approach used and in our sample and none reported any issues regarding privacy. However, the study was performed in a dedicated hospital setting where patients were routinely examined. The option of carrying out remote videoconferences with patients staying at home was not applied; therefore, all ethical implications of home-based cognitive function assessment should be further investigated.

Our study has strengths and limitations. The long duration (24 months) of observation, the well-defined diagnosis, and 
comparable clinical characteristics of all patients, which make the sample quite homogenous, are strengths of our study. In fact, only sparse studies have evaluated MMSE and ADAS-cog by videoconference for follow-up. The presence of two independent and blinded raters with specific experiences should be also positively considered.

On the other side, we recognize that the number of patients investigated is obviously small because this was a pilot study. We are also aware that we observed patients in a hospital setting with the presence of an assistant. This was done to check the audiovisual system. However, we cannot exclude that the same patients could behave differently if they were at home. These limits should be addressed in a future study with a larger sample group.

Despite these possible limitations, the MMSE and ADAS-cog administration via telemedicine is useful to simplify the assessment of patients and to allow wider participation to clinical trials of people living in remote geographical areas. Further research with a larger sample group and a remote geographical location are required.

In conclusion, videoconferencing can be used to assess patients with mild to moderate dementia, document their cognitive stability or decline, and measure the effects of the treatments.

\section{Conflicts of Interest}

None declared.

\section{References}

1. Gutiérrez LM, Arrieta I, Instituto Nacional de Geriatría. 2015 Nov 09. Action plan Alzheimer's disease and other dementia, Mexico URL: http://www.geriatria.salud.gob.mx/descargas/noticias/plan alzheimer.pdf [accessed 2018-04-03] [WebCite Cache ID 6yPAOu3As]

2. Prince M, Wimo A, Guerchet M, Ali G, Prina M. World Alzheimer Report 2015 The Global Impact of Dementia: An Analysis of Prevalence, Incidence, Cost and Trends. London: Alzheimer's Disease International; 2015 Aug. URL: https:/ /www.alz.co.uk/research/WorldAlzheimerReport2015.pdf [accessed 2018-04-03] [WebCite Cache ID 6yPAL4KfK]

3. Alzheimer's Association. 2009 Alzheimer's disease facts and figures. Alzheimers Dement 2009 May;5(3):234-270. [doi: 10.1016/j.jalz.2009.03.001] [Medline: 19426951]

4. Colucci L, Bosco M, Fasanaro AM, Gaeta GL, Ricci G, Amenta F. Alzheimer's disease costs: what we know and what we should take into account. J Alzheimers Dis 2014;42(4):1311-1324. [doi: 10.3233/JAD-131556] [Medline: 25024334]

5. Dal Forno G, Chiovenda P, Bressi F, Ferreri F, Grossi E, Brandt J, et al. Use of an Italian version of the telephone interview for cognitive status in Alzheimer's disease. Int J Geriatr Psychiatry 2006 Feb;21(2):126-133. [doi: 10.1002/gps.1435] [Medline: 16416467]

6. Doody RS, Stevens JC, Beck C, Dubinsky RM, Kaye JA, Gwyther L, et al. Practice parameter: management of dementia (an evidence-based review). Report of the Quality Standards Subcommittee of the American Academy of Neurology. Neurology 2001 May 08;56(9):1154-1166. [Medline: 11342679]

7. McKhann G, Drachman D, Folstein M, Katzman R, Price D, Stadlan EM. Clinical diagnosis of Alzheimer's disease: report of the NINCDS-ADRDA Work Group under the auspices of Department of Health and Human Services Task Force on Alzheimer's Disease. Neurology 1984 Jul;34(7):939-944. [Medline: 6610841]

8. Demaerschalk BM, Raman R, Ernstrom K, Meyer BC. Efficacy of telemedicine for stroke: pooled analysis of the Stroke Team Remote Evaluation Using a Digital Observation Camera (STRokE DOC) and STRokE DOC Arizona telestroke trials. Telemed J E Health 2012 Apr;18(3):230-237 [FREE Full text] [doi: 10.1089/tmj.2011.0116] [Medline: 22400970]

9. Martínez-Alcalá CI, Pliego-Pastrana P, Rosales-Lagarde A, Lopez-Noguerola JS, Molina-Trinidad EM. Information and communication technologies in the care of the elderly: systematic review of applications aimed at patients with dementia and caregivers. JMIR Rehabil Assist Technol 2016 May 02;3(1):e6 [FREE Full text] [doi: 10.2196/rehab.5226] [Medline: $\underline{28582258}]$

10. Van der Roest HG, Wenborn J, Pastink C, Dröes R, Orrell M. Assistive technology for memory support in dementia. Cochrane Database Syst Rev 2017 Dec 11;6:CD009627. [doi: 10.1002/14651858.CD009627.pub2] [Medline: 28602027]

11. O'Connor E, Farrow M, Hatherly C. Randomized comparison of mobile and web-tools to provide dementia risk reduction education: use, engagement and participant satisfaction. JMIR Ment Health 2014;1(1):e4 [FREE Full text] [doi: 10.2196/mental.3654] [Medline: 26543904]

12. Cash M. Assistive technology and people with dementia. Rev Clin Gerontol 1999;13(4):313-319. [doi: 10.1017/S0959259804001169]

13. Lauriks S, Reinersmann A, Van der Roest HG, Meiland FJM, Davies RJ, Moelaert F, et al. Review of ICT-based services for identified unmet needs in people with dementia. Ageing Res Rev 2007 Oct;6(3):223-246. [doi: 10.1016/j.arr.2007.07.002] [Medline: $\underline{17869590]}$

14. Martínez-Alcalá CI, Pliego-Pastrana P, Rosales-Lagarde A, Lopez-Noguerola JS, Molina-Trinidad EM. Information and communication technologies in the care of the elderly: systematic review of applications aimed at patients with dementia and caregivers. JMIR Rehabil Assist Technol 2016 May 02;3(1):e6 [FREE Full text] [doi: 10.2196/rehab.5226] [Medline: 28582258] 
15. Mense A, Steger S, Sulek M, Jukic-Sunaric D, Mészáros A. Analyzing privacy risks of mHealth applications. Stud Health Technol Inform 2016;221:41-45. [Medline: 27071873]

16. Kim H, Jhoo JH, Jang J. The effect of telemedicine on cognitive decline in patients with dementia. J Telemed Telecare 2017 Jan;23(1):149-154. [doi: 10.1177/1357633X15615049] [Medline: 26541171]

17. Timpano F, Pirrotta F, Bonanno L, Marino S, Marra A, Bramanti P, et al. Videoconference-based mini mental state examination: a validation study. Telemed J E Health 2013 Dec;19(12):931-937. [doi: 10.1089/tmj.2013.0035] [Medline: 24073900]

18. Ciemins EL, Holloway B, Coon PJ, McClosky-Armstrong T, Min S. Telemedicine and the mini-mental state examination: assessment from a distance. Telemed J E Health 2009 Jun;15(5):476-478 [FREE Full text] [doi: 10.1089/tmj.2008.0144] [Medline: 19548827]

19. Loh P, Donaldson M, Flicker L, Maher S, Goldswain P. Development of a telemedicine protocol for the diagnosis of Alzheimer's disease. J Telemed Telecare 2007;13(2):90-94. [doi: 10.1258/135763307780096159] [Medline: 17359573]

20. McEachern W, Kirk A, Morgan DG, Crossley M, Henry C. Reliability of the MMSE administered in-person and by telehealth. Can J Neurol Sci 2008 Nov;35(5):643-646. [Medline: 19235450]

21. Loh PK, Ramesh P, Maher S, Saligari J, Flicker L, Goldswain P. Can patients with dementia be assessed at a distance? The use of telehealth and standardised assessments. Intern Med J 2004 May;34(5):239-242. [doi:

10.1111/j.1444-0903.2004.00531.x] [Medline: 15151669]

22. Munro CC, Hynan LS, Grosch M, Parikh M, Weiner MF. Teleneuropsychology: evidence for video teleconference-based neuropsychological assessment. J Int Neuropsychol Soc 2014 Nov;20(10):1028-1033 [FREE Full text] [doi: 10.1017/S1355617714000873] [Medline: 25343269]

23. Montani C, Billaud N, Tyrrell J, Fluchaire I, Malterre C, Lauvernay N, et al. Psychological impact of a remote psychometric consultation with hospitalized elderly people. J Telemed Telecare 1997;3(3):140-145. [doi: 10.1258/1357633971931048] [Medline: $\underline{9489108]}$

24. Magni E, Binetti G, Bianchetti A, Rozzini R, Trabucchi M. Mini-Mental State Examination: a normative study in Italian elderly population. Eur J Neurol 1996 May;3(3):198-202. [doi: 10.1111/j.1468-1331.1996.tb00423.x] [Medline: 21284770]

25. Fioravanti M, Nacca D, Buckley AE, Ferrario E, Varetto O, Mogni P, et al. The Italian version of the Alzheimer's Disease Assessment Scale (ADAS): psychometric and normative characteristics from a normal aged population. Arch Gerontol Geriatr 1994;19(1):21-30. [Medline: 15374291$]$

26. Folstein MF, Folstein SE, McHugh PR. "Mini-mental state". A practical method for grading the cognitive state of patients for the clinician. J Psychiatr Res 1975 Nov;12(3):189-198. [Medline: 1202204]

27. Mitchell AJ. A meta-analysis of the accuracy of the mini-mental state examination in the detection of dementia and mild cognitive impairment. J Psychiatr Res 2009 Jan;43(4):411-431. [doi: 10.1016/j.jpsychires.2008.04.014] [Medline: 18579155]

28. Arevalo-Rodriguez I, Smailagic N, Roqué I, Ciapponi A, Sanchez-Perez E, Giannakou A, et al. Mini-Mental State Examination (MMSE) for the detection of Alzheimer's disease and other dementias in people with mild cognitive impairment (MCI). Cochrane Database Syst Rev 2015 Mar 05(3):CD010783. [doi: 10.1002/14651858.CD010783.pub2] [Medline: 25740785]

29. Rosen WG, Mohs RC, Davis KL. A new rating scale for Alzheimer's disease. Am J Psychiatry 1984 Nov;141(11):1356-1364. [doi: 10.1176/ajp.141.11.1356] [Medline: $\underline{6496779}$ ]

30. Monllau A, Pena-Casanova J, Blesa R, Aguilar M, Bohm P, Sol JM, et al. [Diagnostic value and functional correlations of the ADAS-Cog scale in Alzheimer's disease: data on NORMACODEM project]. Neurologia 2007 Oct;22(8):493-501. [Medline: 17602338$]$

31. Zainal NH, Silva E, Lim LL, Kandiah N. Psychometric properties of Alzheimer's Disease Assessment Scale-Cognitive Subscale for mild cognitive impairment and mild Alzheimer's disease patients in an Asian context. Ann Acad Med Singapore 2016 Jul;45(7):273-283 [FREE Full text] [Medline: 27523508]

32. Kirkwood KT, Peck DF, Bennie L. The consistency of neuropsychological assessments performed via telecommunication and face to face. J Telemed Telecare 2000;6(3):147-151. [Medline: 10912332]

33. De Las Cuevas C, Arredondo MT, Cabrera MF, Sulzenbacher H, Meise U. Randomized clinical trial of telepsychiatry through videoconference versus face-to-face conventional psychiatric treatment. Telemed J E Health 2006 Jun;12(3):341-350. [doi: 10.1089/tmj.2006.12.341] [Medline: 16796502]

34. Dorsey ER, Venkataraman V, Grana MJ, Bull MT, George BP, Boyd CM, et al. Randomized controlled clinical trial of "virtual house calls" for Parkinson disease. JAMA Neurol 2013 May;70(5):565-570 [FREE Full text] [doi: 10.1001/jamaneurol.2013.123] [Medline: 23479138]

35. Durisko C, McCue M, Doyle PJ, Dickey MW, Fiez JA. A flexible and integrated system for the remote acquisition of neuropsychological data in stroke research. Telemed J E Health 2016 Dec;22(12):1032-1040. [doi: 10.1089/tmj.2015.0235] [Medline: 27214198]

36. Castanho TC, Amorim L, Moreira PS, Mariz J, Palha JA, Sousa N, et al. Assessing cognitive function in older adults using a videoconference approach. EBioMedicine 2016 Sep;11:278-284 [FREE Full text] [doi: 10.1016/j.ebiom.2016.08.001] [Medline: 27515687] 
37. Korn RE, Shukla AW, Katz M, Keenan HT, Goldenthal S, Auinger P, et al. Virtual visits for Parkinson disease: a multicenter noncontrolled cohort. Neurol Clin Pract 2017 Aug;7(4):283-295. [doi: 10.1212/CPJ.0000000000000371] [Medline: 28840919]

38. Bernocchi P, Vanoglio F, Baratti D, Morini R, Rocchi S, Luisa A, et al. Home-based telesurveillance and rehabilitation after stroke: a real-life study. Top Stroke Rehabil 2016 Apr;23(2):106-115. [doi: 10.1080/10749357.2015.1120453] [Medline: 27078116]

39. Parikh M, Grosch MC, Graham LL, Hynan LS, Weiner M, Shore JH, et al. Consumer acceptability of brief videoconference-based neuropsychological assessment in older individuals with and without cognitive impairment. Clin Neuropsychol 2013;27(5):808-817 [FREE Full text] [doi: 10.1080/13854046.2013.791723] [Medline: 23607729]

40. Tun PA, Lachman ME. The association between computer use and cognition across adulthood: use it so you won't lose it? Psychol Aging 2010 Sep;25(3):560-568 [FREE Full text] [doi: 10.1037/a0019543] [Medline: 20677884]

41. Zimmer Z, Chappell NL. Receptivity to new technology among older adults. Disabil Rehabil 1999;21(5-6):222-230. [Medline: 10381234$]$

42. Ellis D, Allaire JC. Modeling computer interest in older adults: the role of age, education, computer knowledge, and computer anxiety. Hum Factors 1999 Sep;41(3):345-355. [Medline: 10665203]

43. Johnson RA, Karlawish J. A review of ethical issues in dementia. Int Psychogeriatr 2015 Oct;27(10):1635-1647. [doi: 10.1017/S1041610215000848] [Medline: 26061118]

44. Pennington K. Legal and ethical concerns of digital media and technology in healthcare. Md Med 2015;16(3):29-30. [Medline: 26887074]

45. Wootton R, Liu J, Bonnardot L, Venugopal R, Oakley A. Experience with quality assurance in two store-and-forward telemedicine networks. Front Public Health 2015;3:261 [FREE Full text] [doi: 10.3389/fpubh.2015.00261] [Medline: 26870720]

46. Worth T. Telehealth: the balance between access and ethics. Med Econ 2015 Dec 10;92(23):29-32. [Medline: 26875331]

47. Sabin JE, Skimming K. A framework of ethics for telepsychiatry practice. Int Rev Psychiatry 2015;27(6):490-495. [doi: 10.3109/09540261.2015.1094034] [Medline: 26493214]

48. Chung J, Demiris G, Thompson HJ. Ethical considerations regarding the use of smart home technologies for older adults: an integrative review. Annu Rev Nurs Res 2016;34:155-181. [doi: 10.1891/0739-6686.34.155] [Medline: 26673381]

\title{
Abbreviations
}

AD: Alzheimer's disease

ADAS-cog: Alzheimer's Disease Assessment Scale cognitive subscale

ADL: Activities of Daily Living

IADL: Instrumental Activities of Daily Living

MCI: mild cognitive impairment

MMSE: Mini Mental State Examination

\author{
Edited by J Nicholas; submitted 25.05.17; peer-reviewed by I Rehm, P Sooful; comments to author 25.07.17; revised version received \\ 29.09.17; accepted 26.02.18; published 11.05.18 \\ Please cite as: \\ Carotenuto A, Rea R, Traini E, Ricci G, Fasanaro AM, Amenta F \\ Cognitive Assessment of Patients With Alzheimer's Disease by Telemedicine: Pilot Study \\ JMIR Ment Health 2018;5(2):e31 \\ URL: http://mental.jmir.org/2018/2/e31/ \\ doi: $10.2196 /$ mental.8097 \\ PMID: 29752254
}

(C)Anna Carotenuto, Raffaele Rea, Enea Traini, Giovanna Ricci, Angiola Maria Fasanaro, Francesco Amenta. Originally published in JMIR Mental Health (http://mental.jmir.org), 11.05.2018. This is an open-access article distributed under the terms of the Creative Commons Attribution License (https://creativecommons.org/licenses/by/4.0/), which permits unrestricted use, distribution, and reproduction in any medium, provided the original work, first published in JMIR Mental Health, is properly cited. The complete bibliographic information, a link to the original publication on http://mental.jmir.org/, as well as this copyright and license information must be included. 